University of Wollongong

Research Online

Faculty of Engineering - Papers (Archive)

Faculty of Engineering and Information

Sciences

$1-1-2012$

\title{
Normalized confinement stiffness approach for modeling FRP-confined concrete
}

Veysel Yazici

University of Wollongong, vy210@uow.edu.au

Muhammad N. S Hadi

University of Wollongong, mhadi@uow.edu.au

Follow this and additional works at: https://ro.uow.edu.au/engpapers

Part of the Engineering Commons

https://ro.uow.edu.au/engpapers/5126

\section{Recommended Citation}

Yazici, Veysel and Hadi, Muhammad N. S: Normalized confinement stiffness approach for modeling FRPconfined concrete 2012, 520-528.

https://ro.uow.edu.au/engpapers/5126

Research Online is the open access institutional repository for the University of Wollongong. For further information contact the UOW Library: research-pubs@uow.edu.au 

Modeling FRP Confined Concrete

\author{
Veysel Yazici ${ }^{1}$; and Muhammad N. S. Hadi
}

\begin{abstract}
Passive confinement provided by fiber-reinforced polymer (FRP) jackets increases the compressive strength and axial deformation capacity of concrete. This study explains a normalized confinement stiffness approach to quantify the strength and strain increase of FRP confined concrete using a previously-proposed and most widely-used model for both active and passive confinement of concrete, and claims that these equations can still be used for FRP confined concrete with very simple modifications. A comparison of the proposed model's accuracy to ACI440.2R-02 and ACI440.R-08 guidelines was made using experimental results reported in the literature. The proposed modified model was shown to be quite effective in predicting the increased strength and strain values of FRP confined concrete, and was also modified for FRP confined hollow concrete cylinders. DOI: 10.1061/(ASCE)CC.1943-5614.0000283. @ 2012 American Society of Civil Engineers.
\end{abstract}

CE Database subject headings: Fiber-reinforced polymer; Stiffness; Stress; Strain; Confinement; Columns.

Author keywords: FRP confined concrete; Confinement stiffness; Ultimate stress; Ultimate strain; Passive confinement; Hollow columns.

\section{Introduction}

The beneficial effect of lateral confinement on the strength and deformation capacity of concrete has been accepted by engineers since Considère (1906). Attempts to quantify the increase in strength and axial strain capacity of confined concrete has been an ongoing subject of research since Richart et al. $(1928,1929)$. With the introduction of fiber-reinforced polymer (FRP) materials into confined concrete applications, many studies have been executed to explain the effect of passive confinement provided by FRP jackets on the behavior of concrete under axial compression.

Considering the lack of generally-accepted strength and strain equations for FRP confined concrete, this research aims to prove that existing equations for confined steel and actively confined concrete can also be used for FRP confinement.

This study presents a confinement stiffness based approach to determine the axial stress and strain capacity increase attributable to FRP wrapping of concrete cylinders. To determine the model's accuracy, experimental results previously reported by various researchers were used. The proposed model's applicability to hollow concrete columns under passive confinement by FRP was also investigated.

\section{Theoretical Background}

Concrete behavior under axial compression and active confinement stress has been studied by various researchers (Balmer 1949;

Ph.D. Candidate, School of Civil, Mining and Environmental Engineering, Univ. of Wollongong, Wollongong, NSW 2522, Australia. E-mail: vy210@uowmail.edu.au

Associate Professor in Structural Engineering, School of Civil, Mining and Environmental Engineering, Univ. of Wollongong, Wollongong, NSW 2522, Australia (corresponding author). E-mail: mhadi@uow.edu.au

Note. This manuscript was submitted on July 4, 2011; approved on January 31, 2012; published online on February 3, 2012. Discussion period open until March 1, 2013; separate discussions must be submitted for individual papers. This paper is part of the Journal of Composites for Construction, Vol. 16, No. 5, October 1, 2012. C) ASCE, ISSN 1090-0268/ 2012/5-0-0/\$25.00.
Candappa et al. 1999; Gardner 1969; Imran and Pantazopoulou 1996; Richart et al. 1928; Sfer et al. 2002; Smith et al. 1989; Xie et al. 1995). In these studies, concrete cylinders were tested under axial compression $\left(\sigma_{1}\right)$ in a pressurized chamber, in which hydraulic confinement pressure $\left(\sigma_{3}\right)$ was kept constant throughout the test. The chamber pressure was first increased to the desired level $\left(f_{l}\right)$, and axial stress was applied to the concrete column while confinement pressure was kept constant (Fig. 1(a)). If the loading path of these tests are drawn on a graph which features the horizontal axis as confinement stress $\left(\sigma_{3}\right)$, and vertical axis as axial stress $\left(\sigma_{1}\right)$, between the points $\mathrm{O}$ and $\mathbf{M}$, axial stress is increasing under the given level of confinement. However, the level of confinement stress is only enough to keep the axial stress increasing until a level of $f_{c c}^{\prime}$ at point $\mathrm{M}$ : see Fig. 1(a and b). Thus, if a point of loading lies on the path O-M, the implication is that the confined concrete strength has yet to be reached. After point M, the axial stress applied to the concrete column decreases despite the unchanged level of confinement stress until point $\mathrm{F}$, at which the concrete cylinder's axial load capacity is significantly decreased and accepted to have failed. The loading path of an unconfined concrete cylinder under axial compression lies only on the vertical axis of Fig. 1(a) and passes through the points $\mathrm{O}$, an unconfined compressive strength at point $\mathrm{A}$, and an accepted level of failure stress at point B.

To determine the axial stress value at point $M$ and the corresponding axial strain under a given constant confinement pressure, Richart et al. (1928) proposed Eqs. 1 and 2, which were developed empirically. The unconfined concrete strength used in this study varied from 20-50 $\mathrm{MPa}$.

$$
\begin{gathered}
\frac{f_{c c}^{\prime}}{f_{c o}^{\prime}}=1+4.1 \frac{f_{l}}{f_{c o}^{\prime}} \\
\frac{\varepsilon_{c c}}{\varepsilon_{c o}}=1+5\left(\frac{f_{c c}^{\prime}}{f_{c o}^{\prime}}-1\right)
\end{gathered}
$$

Mander et al. (1988a) proposed Eq. 3 for calculating confined concrete strength $\left(f_{c c}^{\prime}\right)$ at a given constant confining stress $f_{l}$; thus, Eq. 3 can be assumed to give the position of point $\mathrm{M}$ for any given 


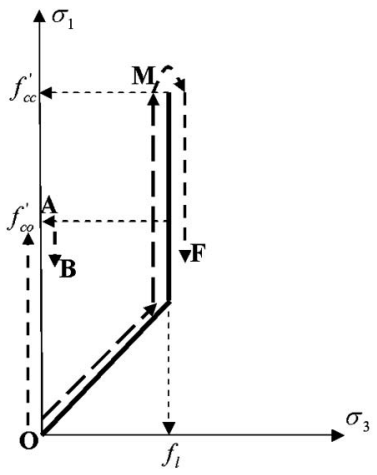

(a)

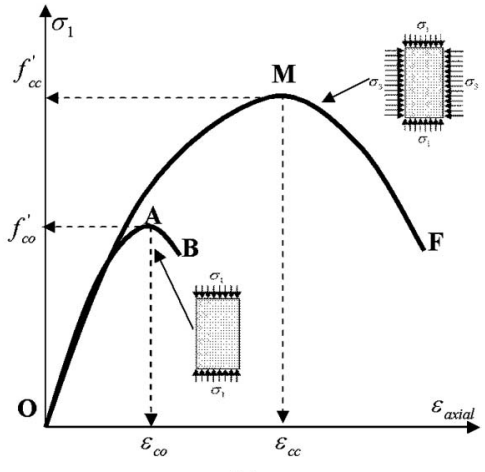

(b)

F1:1 Fig. 1. (a) Loading paths for axially-loaded concrete with constant F1:2 confining pressure and without confinement; (b) Axial stress-strain F1:3 diagram for axially-loaded concrete with constant confining pressure F1:4 and without confinement

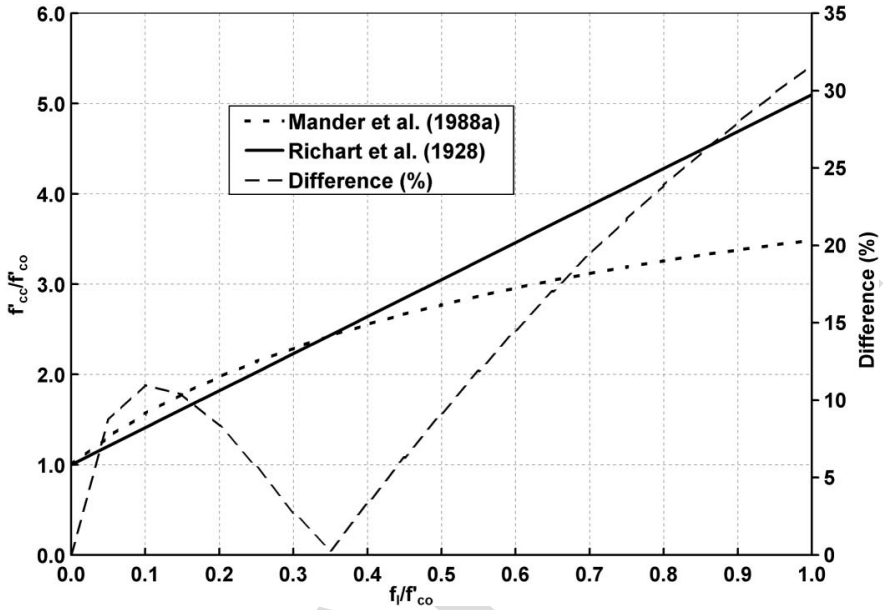

Fig. 2. Confined concrete strength predictions using models proposed by Richart et al. (1928) and Mander et al. (1988b), and the absolute difference between predictions

paths. The intersection point values and the exact shape of the loading path depend on the radial expansion rate of passively-confined concrete in addition to the stress-strain behavior of the confining material under tensile stress. Iterative methods to determine the relationship between any axial stress level and the corresponding confinement stress on the concrete, by using the compatibility equations between the concrete and confining materials to establish a full stress-strain graph of passively-confined concrete, has been successfully adopted by several researchers (Fam and Rizkalla 2001; Lignola et al. 2008; Spoelstra and Monti 1999). Since this study is only focused on the ultimate strength and corresponding axial strain of passively-confined concrete cylinders by FRP, determining the intersection points of loading paths other than that corresponding to the confined strength of concrete $\left(f_{c c}^{\prime}\right)$ are beyond the scope of this study.

For steel confined concrete, the ultimate confinement stress is reached when the confinement steel reaches its yielding strain, thus providing a constant confinement after this point. However, for FRP materials which exhibit a linear stress-strain relationship, there is no yielding point (unlike steel), and the maximum confinement stress depends on other factors which will be explained in the next part of this study.

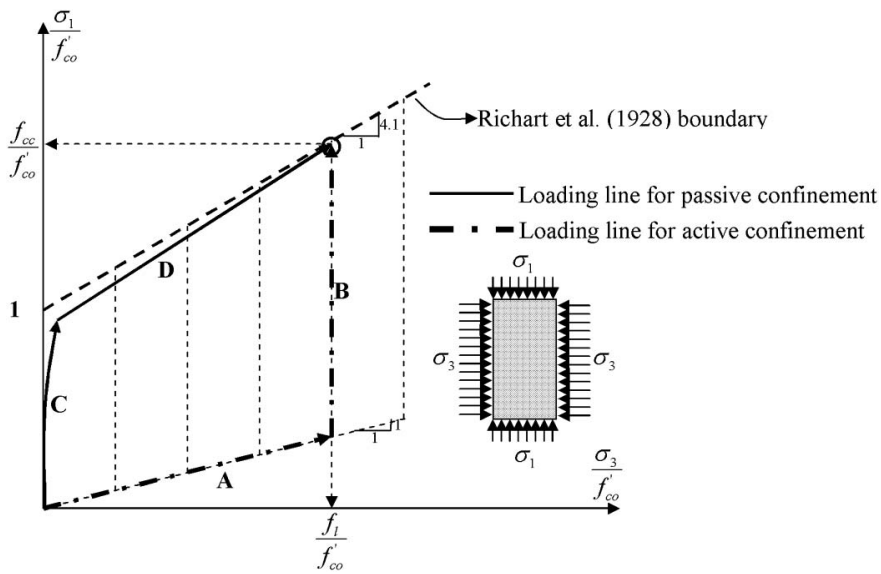

constant confinement pressure. The non-linear relationship between confined concrete strength and constant confinement pressure given in Eq. 3 was based on the ultimate surface developed by Elwi and Murray (1979), and calibrated using triaxial (constant confinement pressure) test data. However, the equation proposed by Mander et al. (1988a) for the corresponding strain was identical to Richart et al. (1928) Eq. 2. Because this was a parametric model, theoretically there is no concrete strength limitation for Eq. 3.

$$
\frac{f_{c c}^{\prime}}{f_{c o}^{\prime}}=2.254 \sqrt{1+7.94 \frac{f_{l}}{f_{c o}^{\prime}}}-2 \frac{f_{l}}{f_{c o}^{\prime}}-1.254
$$

Although these two ultimate strength equations (Eqs. 1 and 3) were developed by different researchers using different approaches, they yield very similar predictions for small confinement stresses. Up to confinement stress levels $\left(f_{l}: f_{c o}^{\prime}\right)$ of 0.7 , Mander et al. (1988a) model predicts confined concrete strength values with absolute differences of below $20 \%$, relative to Richart et al. (1928) model (Fig. 2).

Both equations 1 and 3 were also applied to concrete columns passively confined by steel bars, and found to be suitable in predicting the confined strength of passively-confined concrete (Mander et al. 1988b; Richart et al. 1929).

The explanation for the suitability of a confinement model developed using a constant confinement pressure (active confinement) to steel confined concrete (passive confinement) was given by Imran and Pantazopoulou (1996) and Lan and Guo (1997). These researchers reported that confined concrete strength was essentially independent of the shape of the loading path. The pathindependency of confined concrete strength implies that either Richart et al. (1928) or Mander et al. (1988a) equations (Eqs. 1 and 3, respectively) can still be taken as a boundary for passivelyconfined concrete, as shown in Fig. 3 for Richart et al.'s (1928) model.

The critical point for the applicability of active confinement models to passive confinement is to determine the confinement stress ratio $\left(f_{l}: f_{c o}^{\prime}\right)$ at the point of maximum axial stress.

For passively-confined concrete, radial expansion is very low point, the confinement stress is very low. However, after the axial stress value of $f_{c o}^{\prime}$ is exceeded (one on the vertical axis of Fig. 3), the confinement pressure rapidly increases, attributable to radial expansion of the concrete cylinder with increasing axial stress, and the loading path begins to intersect the constant pressure loading until the unconfined concrete strength is reached. Thus, until this

Fig. 3. Loading lines for active and passive confinement (not in scale)

F $2: 1$

$\mathrm{F} 2: 2$

$\mathrm{F} 2: 3$

110

111

112

113

114

115

116

117

118

119

120

121

122

123

124

125

126

127

128

129

130

131 


\section{FRP Confined Concrete}

Strengthening of concrete columns with FRP has become a common practice of passive confinement applications; however, there is still no internationally-agreed design guideline or standards. Currently, "The guide for the design and construction of externally bonded FRP systems for strengthening concrete structures" reported by ACI Committee 440 is the most accepted.

In the previous version of the guideline (ACI440.2R-02 2002), the ACI 440 committee had recommended Eq. 3, proposed by Mander et al. (1988a), to predict the FRP confined strength of concrete, although the equation was originally proposed for steel confined concrete. Considering the loading path independency reported by Imran and Pantazopoulou (1996) and Lan and Guo (1997), using Eq. 3 would have given good estimations for FRP confined concrete strength, assuming that the FRP confining device fails at the same hoop strain as in uniaxial coupon tests. However, the FRP confining device's failure strain values varies from 58$61 \%$ of the coupon test strains, primarily based on carbon FRP confinement (De Lorenzis and Tepfers 2001, 2003; Harries and Carey 2003; Lam and Teng 2003a; Matthys 2001; Pessiki et al. 2001). This is attributable to the multiaxial state of stress of the FRP confinement device and possible stress concentrations throughout the surface of the concrete column. To be able to use Mander et al. (1988a) Eq. 1 to predict the confined strength of concrete, the actual confining stress $\left(f_{l}\right)$ at the time of the confined concrete's peak axial stress should be known, because this equation was derived assuming that the confinement stress is definitely known and equal to a constant confining pressure.

In the current version of ACI 440.2R (2008), the premature failure of FRP confinement is considered, and rather than Mander et al. (1988a) Eq. 3, it is recommended to predict the confined strength of concrete for circular cross-sections by using the Eqs. 4 and 5 proposed by Lam and Teng (2003a), especially for FRP confined concrete, with an additional reduction factor of $\psi_{f}=0.95$. However, to use Eq. 5 for prediction purposes, the value of $\psi_{f}$ was taken as 1.0 as it was originally proposed by Lam and Teng (2003a):

$$
\begin{gathered}
\frac{f_{c c}^{\prime}}{f_{c o}^{\prime}}=1+\psi_{f} 3.3 \frac{f_{l}}{f_{c o}^{\prime}} \\
f_{l}=\frac{2 E_{f} t_{f} \varepsilon_{f e}}{D}
\end{gathered}
$$

where $E_{f}$ is the modulus of elasticity, $t_{f}$ is total thickness, $\varepsilon_{f e}$ is the effective strain value at the time of failure of the FRP confinement device; and $D$ is the diameter of the concrete cylinder. The effective strain value of FRP confinement is given by:

$$
\varepsilon_{f e}=\kappa_{\varepsilon} \varepsilon_{f u}
$$

where $\kappa_{\varepsilon}$ is the strain efficiency factor (a value of 0.55 is recommended for circular cross-sections) and $\varepsilon_{f u}$ is the ultimate tensile strain value of the FRP confinement material measured in coupon tests.

Based on the tests done by Lam and Teng (2003a, b), ACI $440.2 \mathrm{R}$ (2008) recommends that the confinement ratio $\left(f_{l}: f_{c o}^{\prime}\right)$ should be larger than 0.08 to ensure a nondescending stress-strain graph, which can be taken as a lower limit for the confinement ratio.

For circular cross-sections, ACI 440.2R (2008) recommends Eq. 7 for predicting the axial strain of concrete corresponding to the maximum axial stress $\left(\varepsilon_{c c}\right)$; however, this value is restricted to a maximum value of 0.01 to prevent excessive cracking and maintain structural integrity.

$$
\varepsilon_{c c}=\varepsilon_{c o}\left(1.50+12 \frac{f_{l}}{f_{c o}^{\prime}}\left(\frac{\varepsilon_{f e}}{\varepsilon_{c o}}\right)^{0.45}\right)
$$

Assuming an $\varepsilon_{c o}$ value of 0.002 , an average $\varepsilon_{f u}$ value of 0.0145 for carbon FRP (calculated from the values given in Table 1), and calculating $\varepsilon_{f e}$ from Eq. 6, the upper boundary for the confinement ratio $\left(f_{l}: f_{c o}^{\prime}\right)$ was calculated as 0.16 using the limitation of $\varepsilon_{c c}$ to 0.01 in Eq. 5. Thus, the lower and upper boundaries of $f_{l}: f_{c o}^{\prime}$ are given in Eq. 8:

$$
0.08 \leq \frac{f_{l}}{f_{c o}^{\prime}} \leq 0.16
$$

This study assumes that when the premature failure of FRP confinement is considered the ultimate strength and corresponding axial strain of FRP confined concrete can be predicted using the model for active and passive confinement of concrete proposed by Richart et al. (1928, 1929). The reason for preferring Richart et al. $(1928,1929)$ is that, in practice, achieving passive confinement ratios $\left(f_{l}: f_{c o}^{\prime}\right)$ as large as 0.7 is quite difficult, considering the larger size of real concrete columns relative to test specimens and the cost of confinement materials (this paper previously explained that up to the confinement ratio 0.7 , the difference between predicted values using the two models is below 20\%). Moreover, when it is considered that ACI 440.2R (2008) recommends the upper and lower limits given in Eq. 8 in designs, using Richart et al. (1928) model for predicting the behavior of passively-confined concrete yields more conservative results than Mander et al. (1988a) model.

Richart et al. (1928) Eqs. 1 and 2 were modified to account for the premature failure of FRP confinement and used for predicting FRP confined concrete.

In Eq. 1 and 2, instead of using the confinement ratio, $f_{l}: f_{c o}^{\prime}$, a normalized confinement stiffness $\left(K_{N}\right)$ given by Eq. 9 was used to express the confined concrete strength and corresponding strain:

$$
K_{N}=\frac{2 E_{f} t_{f}}{D f_{c o}^{\prime}}
$$

The confinement ratio expression $\left(f_{l}: f_{c o}^{\prime}\right)$ in Eq. 1 can be rewritten, as shown in Eq. 10:

$$
\frac{f_{l}}{f_{c o}^{\prime}}=\kappa_{\varepsilon} \varepsilon_{f u} K_{N}
$$

Inserting Eq. 10 into Eq. 1, and using $\kappa_{\varepsilon}=0.55$ in addition to an average value of 0.0145 for $\varepsilon_{f u}$-calculated by taking the average value of carbon FRP coupon failure strains of 85 samples as shown in Table 1 - the equations simplify as shown in Eqs. 11 and 12. The upper and lower limits of the confinement ratios $\left(f_{l}: f_{c o}^{\prime}\right)$ recommended by ACI 440.2R (2008) were also re-written in terms of $K_{N}$ and are given in Eq. 13:

$$
\begin{gathered}
\frac{f_{c c}^{\prime}}{f_{c o}^{\prime}}=1+0.033 K_{N} \\
\frac{\varepsilon_{c c}}{\varepsilon_{c o}}=1+0.16 K_{N} \\
10 \leq K_{N} \leq 20
\end{gathered}
$$

\section{Database for Model Comparison}

In the majority of reported experimental studies, carbon FRP sheets were used to confine the cylinder specimens; thus, only the carbon FRP wrapped concrete cylinders were taken into the database for 
Table 1. Database of Carbon FRP Confined Concrete Cylinders for Model Development

\begin{tabular}{|c|c|c|c|c|c|c|c|c|c|c|c|}
\hline $\mathrm{T} 1: 1$ & Number & Source of data & $D(\mathrm{~mm})$ & $f_{c o}^{\prime}(\mathrm{MPa})$ & $\varepsilon_{c o}(\%)$ & $t_{f}(\mathrm{~mm})$ & $E_{f}(\mathrm{GPa})$ & $f_{f}(\mathrm{MPa})$ & $K_{N}$ & $f_{c c}^{\prime}(\mathrm{MPa})$ & $\varepsilon_{c c}(\%)$ \\
\hline $\mathrm{T} 1: 2$ & 1 & Xiao and Wu (2000) & 152 & 33.7 & 0.25 & 0.38 & 105 & 1,577 & 15.6 & 47.9 & 1.20 \\
\hline $\mathrm{T} 1: 3$ & 2 & Xiao and Wu (2000) & 152 & 33.7 & 0.25 & 0.38 & 105 & 1,577 & 15.6 & 49.7 & 1.40 \\
\hline $\mathrm{T} 1: 4$ & 3 & Xiao and Wu (2000) & 152 & 33.7 & 0.25 & 0.38 & 105 & 1,577 & 15.6 & 49.4 & 1.24 \\
\hline $\mathrm{T} 1: 5$ & 4 & Xiao and Wu (2000) & 152 & 33.7 & 0.25 & 0.76 & 105 & 1,577 & 31.2 & 64.6 & 1.65 \\
\hline $\mathrm{T} 1: 6$ & 5 & Xiao and Wu (2000) & 152 & 33.7 & 0.25 & 0.76 & 105 & 1,577 & 31.2 & 75.2 & 2.25 \\
\hline $\mathrm{T} 1: 7$ & 6 & Xiao and $\mathrm{Wu}(2000)$ & 152 & 33.7 & 0.25 & 0.76 & 105 & 1,577 & 31.2 & 71.8 & 2.16 \\
\hline $\mathrm{T} 1: 8$ & 7 & Xiao and Wu (2000) & 152 & 33.7 & 0.25 & 1.14 & 105 & 1,577 & 46.7 & 82.9 & 2.45 \\
\hline $\mathrm{T} 1: 9$ & 8 & Xiao and Wu (2000) & 152 & 33.7 & 0.25 & 1.14 & 105 & 1,577 & 46.7 & 95.4 & 3.03 \\
\hline $\mathrm{T} 1: 10$ & 9 & Xiao and Wu (2000) & 152 & 43.8 & 0.23 & 0.38 & 105 & 1,577 & 12.0 & 54.8 & 0.60 \\
\hline $\mathrm{T} 1: 11$ & 10 & Xiao and Wu (2000) & 152 & 43.8 & 0.23 & 0.38 & 105 & 1,577 & 12.0 & 52.1 & 0.39 \\
\hline $\mathrm{T} 1: 12$ & 11 & Xiao and Wu (2000) & 152 & 43.8 & 0.23 & 0.76 & 105 & 1,577 & 24.0 & 84.0 & 1.57 \\
\hline $\mathrm{T} 1: 13$ & 12 & Xiao and Wu (2000) & 152 & 43.8 & 0.23 & 0.76 & 105 & 1,577 & 24.0 & 79.2 & 1.37 \\
\hline $\mathrm{T} 1: 14$ & 13 & Xiao and Wu (2000) & 152 & 43.8 & 0.23 & 0.76 & 105 & 1,577 & 24.0 & 85.0 & 1.66 \\
\hline $\mathrm{T} 1: 15$ & 14 & Xiao and $\mathrm{Wu}(2000)$ & 152 & 43.8 & 0.23 & 1.14 & 105 & 1,577 & 36.0 & 96.5 & 1.74 \\
\hline $\mathrm{T} 1: 16$ & 15 & Xiao and Wu (2000) & 152 & 43.8 & 0.23 & 1.14 & 105 & 1,577 & 36.0 & 92.6 & 1.68 \\
\hline $\mathrm{T} 1: 17$ & 16 & Xiao and Wu (2000) & 152 & 43.8 & 0.23 & 1.14 & 105 & 1,577 & 36.0 & 94.0 & 1.75 \\
\hline $\mathrm{T} 1: 18$ & 17 & Xiao and $\mathrm{Wu}(2000)$ & 152 & 55.2 & 0.27 & 0.38 & 105 & 1,577 & 9.5 & 57.9 & 0.28 \\
\hline $\mathrm{T} 1: 19$ & 18 & Xiao and Wu (2000) & 152 & 55.2 & 0.27 & 0.38 & 105 & 1,577 & 9.5 & 58.1 & 0.31 \\
\hline $\mathrm{T} 1: 20$ & 19 & Xiao and Wu (2000) & 152 & 55.2 & 0.27 & 0.38 & 105 & 1,577 & 9.5 & 62.9 & 0.41 \\
\hline $\mathrm{T} 1: 21$ & 20 & Xiao and Wu (2000) & 152 & 55.2 & 0.27 & 0.76 & 105 & 1,577 & 19.0 & 74.6 & 0.39 \\
\hline $\mathrm{T} 1: 22$ & 21 & Xiao and Wu (2000) & 152 & 55.2 & 0.27 & 0.76 & 105 & 1,577 & 19.0 & 77.6 & 0.81 \\
\hline $\mathrm{T} 1: 23$ & 22 & Xiao and Wu (2000) & 152 & 55.2 & 0.27 & 1.14 & 105 & 1,577 & 28.5 & 106.5 & 1.43 \\
\hline $\mathrm{T} 1: 24$ & 23 & Xiao and Wu (2000) & 152 & 55.2 & 0.27 & 1.14 & 105 & 1,577 & 28.5 & 108.0 & 1.45 \\
\hline $\mathrm{T} 1: 25$ & 24 & Xiao and Wu (2000) & 152 & 55.2 & 0.27 & 1.14 & 105 & 1,577 & 28.5 & 103.3 & 1.18 \\
\hline $\mathrm{T} 1: 26$ & 25 & Watanabe et al. (1997) & 100 & 30.2 & 0.23 & 0.17 & 224.6 & 2,716 & 25.3 & 46.6 & 1.51 \\
\hline $\mathrm{T} 1: 27$ & 26 & Watanabe et al. (1997) & 100 & 30.2 & 0.23 & 0.5 & 224.6 & 2,873 & 74.4 & 87.2 & 3.11 \\
\hline $\mathrm{T} 1: 28$ & 27 & Watanabe et al. (1997) & 100 & 30.2 & 0.23 & 0.67 & 224.6 & 2,658 & 99.7 & 104.6 & 4.15 \\
\hline $\mathrm{T} 1: 29$ & 28 & Matthys et al. (1999) & 150 & 34.9 & 0.21 & 0.12 & 200 & 2,600 & 9.2 & 44.3 & 0.85 \\
\hline $\mathrm{T} 1: 30$ & 29 & Matthys et al. (1999) & 150 & 34.9 & 0.21 & 0.12 & 200 & 2,600 & 9.2 & 42.2 & 0.72 \\
\hline $\mathrm{T} 1: 31$ & 30 & Rochette and Labosierre (2000) & 100 & 42.0 & $0.22^{\mathrm{a}}$ & 0.6 & 82.7 & 1,265 & 23.6 & 73.5 & 1.65 \\
\hline $\mathrm{T} 1: 32$ & 31 & Rochette and Labosierre (2000) & 100 & 42.0 & $0.22^{\mathrm{a}}$ & 0.6 & 82.7 & 1,265 & 23.6 & 73.5 & 1.57 \\
\hline $\mathrm{T} 1: 33$ & 32 & Rochette and Labosierre (2000) & 100 & 42.0 & $0.22^{\mathrm{a}}$ & 0.6 & 82.7 & 1,265 & 23.6 & 67.9 & 1.35 \\
\hline $\mathrm{T} 1: 34$ & 33 & De Lorenzis et al. (2002) & 120 & 43.0 & $0.22^{\mathrm{a}}$ & 0.3 & 91.1 & 1,028 & 10.6 & 58.5 & 0.87 \\
\hline $\mathrm{T} 1: 35$ & 34 & De Lorenzis et al. (2002) & 120 & 43.0 & $0.22^{\mathrm{a}}$ & 0.3 & 91.1 & 1,028 & 10.6 & 65.6 & 0.82 \\
\hline $\mathrm{T} 1: 36$ & 35 & De Lorenzis et al. (2002) & 150 & 38.0 & $0.21^{\mathrm{a}}$ & 0.45 & 91.1 & 1,028 & 14.4 & 62.0 & 0.71 \\
\hline $\mathrm{T} 1: 37$ & 36 & De Lorenzis et al. (2002) & 150 & 38.0 & $0.21^{\mathrm{a}}$ & 0.45 & 91.1 & 1,028 & 14.4 & 67.3 & 1.24 \\
\hline $\mathrm{T} 1: 38$ & 37 & Lam and Teng (2004) & 152 & 35.9 & 0.20 & 0.165 & 250.5 & 3,762 & 15.1 & 47.2 & 1.11 \\
\hline $\mathrm{T} 1: 39$ & 38 & Lam and Teng (2004) & 152 & 35.9 & 0.20 & 0.165 & 250.5 & 3,762 & 15.1 & 53.2 & 1.29 \\
\hline $\mathrm{T} 1: 40$ & 39 & Lam and Teng (2004) & 152 & 35.9 & 0.20 & 0.165 & 250.5 & 3,762 & 15.1 & 50.4 & 1.27 \\
\hline $\mathrm{T} 1: 41$ & 40 & Lam and Teng (2004) & 152 & 35.9 & 0.20 & 0.33 & 250.5 & 3,762 & 30.3 & 71.6 & 1.85 \\
\hline $\mathrm{T} 1: 42$ & 41 & Lam and Teng (2004) & 152 & 35.9 & 0.20 & 0.33 & 250.5 & 3,762 & 30.3 & 68.7 & 1.68 \\
\hline $\mathrm{T} 1: 43$ & 42 & Lam and Teng (2004) & 152 & 35.9 & 0.20 & 0.33 & 250.5 & 3,762 & 30.3 & 69.9 & 1.96 \\
\hline $\mathrm{T} 1: 44$ & 43 & Lam and Teng (2004) & 152 & 34.3 & 0.19 & 0.495 & 250.5 & 3,762 & 47.6 & 82.6 & 2.05 \\
\hline $\mathrm{T} 1: 45$ & 44 & Lam and Teng (2004) & 152 & 34.3 & 0.19 & 0.495 & 250.5 & 3,762 & 47.6 & 90.4 & 2.41 \\
\hline $\mathrm{T} 1: 46$ & 45 & Lam and Teng (2004) & 152 & 34.3 & 0.19 & 0.495 & 250.5 & 3,762 & 47.6 & 97.3 & 2.52 \\
\hline $\mathrm{T} 1: 47$ & 46 & Lam et al. (2006) & 152 & 41.1 & 0.26 & 0.165 & 250 & 3,800 & 13.2 & 52.6 & 0.90 \\
\hline $\mathrm{T} 1: 48$ & 47 & Lam et al. (2006) & 152 & 41.1 & 0.26 & 0.165 & 250 & 3,800 & 13.2 & 57.0 & 1.21 \\
\hline $\mathrm{T} 1: 49$ & 48 & Lam et al. (2006) & 152 & 41.1 & 0.26 & 0.165 & 250 & 3,800 & 13.2 & 55.4 & 1.11 \\
\hline $\mathrm{T} 1: 50$ & 49 & Lam et al. (2006) & 152 & 38.9 & 0.25 & 0.33 & 247 & 3,754 & 27.6 & 76.8 & 1.91 \\
\hline $\mathrm{T} 1: 51$ & 50 & Lam et al. (2006) & 152 & 38.9 & 0.25 & 0.33 & 247 & 3,754 & 27.6 & 79.1 & 2.08 \\
\hline $\mathrm{T} 1: 52$ & 51 & Lam et al. (2006) & 152 & 38.9 & 0.25 & 0.33 & 247 & 3,754 & 27.6 & 65.8 & 1.25 \\
\hline $\mathrm{T} 1: 53$ & 52 & Jiang and Teng (2007) & 152 & 38.0 & 0.22 & 0.68 & 240.7 & 3,615 & 56.7 & 110.1 & 2.55 \\
\hline $\mathrm{T} 1: 54$ & 53 & Jiang and Teng (2007) & 152 & 38.0 & 0.22 & 0.68 & 240.7 & 3,615 & 56.7 & 107.4 & 2.61 \\
\hline $\mathrm{T} 1: 55$ & 54 & Jiang and Teng (2007) & 152 & 38.0 & 0.22 & 1.02 & 240.7 & 3,615 & 85.0 & 129.0 & 2.79 \\
\hline $\mathrm{T} 1: 56$ & 55 & Jiang and Teng (2007) & 152 & 38.0 & 0.22 & 1.02 & 240.7 & 3,615 & 85.0 & 135.7 & 3.08 \\
\hline $\mathrm{T} 1: 57$ & 56 & Jiang and Teng (2007) & 152 & 37.7 & 0.28 & 0.11 & 260 & 3,905 & 10.0 & 48.5 & 0.90 \\
\hline $\mathrm{T} 1: 58$ & 57 & Jiang and Teng (2007) & 152 & 37.7 & 0.28 & 0.11 & 260 & 3,905 & 10.0 & 50.3 & 0.91 \\
\hline $\mathrm{T} 1: 59$ & 58 & Jiang and Teng (2007) & 152 & 44.2 & 0.26 & 0.11 & 260 & 3,905 & 8.5 & 48.1 & 0.69 \\
\hline $\mathrm{T} 1: 60$ & 59 & Jiang and Teng (2007) & 152 & 44.2 & 0.26 & 0.11 & 260 & 3,905 & 8.5 & 51.1 & 0.89 \\
\hline $\mathrm{T} 1: 61$ & 60 & Jiang and Teng (2007) & 152 & 44.2 & 0.26 & 0.22 & 260 & 3,762 & 17.0 & 65.7 & 1.30 \\
\hline $\mathrm{T} 1: 62$ & 61 & Jiang and Teng (2007) & 152 & 44.2 & 0.26 & 0.22 & 260 & 3,762 & 17.0 & 62.9 & 1.03 \\
\hline $\mathrm{T} 1: 63$ & 62 & Jiang and Teng (2007) & 152 & 47.6 & 0.28 & 0.33 & 250.5 & 3,762 & 22.9 & 82.7 & 1.30 \\
\hline T1:64 & 63 & Jiang and Teng (2007) & 152 & 47.6 & 0.28 & 0.33 & 250.5 & 755 & 22.9 & 85.5 & 1.94 \\
\hline $\mathrm{T} 1: 65$ & 64 & Jiang and Teng (2007) & 152 & 47.6 & 0.28 & 0.33 & 250.5 & 755 & 22.9 & 85.5 & 1.82 \\
\hline $\mathrm{T} 1: 66$ & 65 & Howie and Karbhari (1994) & 152 & 38.6 & 0.21 & 0.31 & 73.3 & 755 & 7.7 & 45.5 & NR \\
\hline $\mathrm{T} 1: 67$ & 66 & Howie and Karbhari (1994) & 152 & 38.6 & 0.21 & 0.31 & 73.3 & 1,047 & 7.7 & 41.9 & NR \\
\hline $\mathrm{T} 1: 68$ & 67 & Howie and Karbhari (1994) & 152 & 38.6 & 0.21 & 0.31 & 73.3 & 1,047 & 7.7 & 47.2 & NR \\
\hline
\end{tabular}


Table 1. (Continued.)

\begin{tabular}{lcccccccccc}
\hline Number & Source of data & $D(\mathrm{~mm})$ & $f_{c o}^{\prime}(\mathrm{MPa})$ & $\varepsilon_{c o}(\%)$ & $t_{f}(\mathrm{~mm})$ & $E_{f}(\mathrm{GPa})$ & $f_{f}(\mathrm{MPa})$ & $K_{N}$ & $f_{c c}^{\prime}(\mathrm{MPa})$ & $\varepsilon_{c c}(\%)$ \\
\hline 68 & Howie and Karbhari (1994) & 152 & 38.6 & 0.21 & 0.61 & 70.6 & 1,047 & 14.7 & 56.5 \\
69 & Howie and Karbhari (1994) & 152 & 38.6 & 0.21 & 0.61 & 70.6 & 1,105 & 14.7 & 60.6 & $\mathrm{NR}$ \\
70 & Howie and Karbhari (1994) & 152 & 38.6 & 0.21 & 0.61 & 70.6 & 1,105 & 14.7 & 61.9 & $\mathrm{NR}$ \\
71 & Howie and Karbhari (1994) & 152 & 38.6 & 0.21 & 0.92 & 77.5 & 1,105 & 24.3 & 80.9 & $\mathrm{NR}$ \\
72 & Howie and Karbhari (1994) & 152 & 38.6 & 0.21 & 0.92 & 77.5 & 1,352 & 24.3 & 76.4 & NR \\
73 & Howie and Karbhari (1994) & 152 & 38.6 & 0.21 & 0.92 & 77.5 & 1,352 & 24.3 & 75.8 & $\mathrm{NR}$ \\
74 & Howie and Karbhari (1994) & 152 & 38.6 & 0.21 & 1.22 & 95.7 & 1,352 & 39.8 & 89.5 & NR \\
75 & Howie and Karbhari (1994) & 152 & 38.6 & 0.21 & 1.22 & 95.7 & 660 & 39.8 & 89.9 & $\mathrm{NR}$ \\
76 & Howie and Karbhari (1994) & 152 & 38.6 & 0.21 & 1.22 & 95.7 & 660 & 39.8 & 89.0 & NR \\
77 & Howie and Karbhari (1994) & 152 & 38.6 & 0.21 & 0.61 & 39.9 & 660 & 8.3 & 47.1 & NR \\
78 & Howie and Karbhari (1994) & 152 & 38.6 & 0.21 & 0.61 & 39.9 & 822 & 8.3 & 47.7 & NR \\
79 & Howie and Karbhari (1994) & 152 & 38.6 & 0.21 & 0.61 & 39.9 & 822 & 8.3 & 50.0 & NR \\
80 & Howie and Karbhari (1994) & 152 & 38.6 & 0.21 & 0.92 & 54 & 822 & 16.9 & 68.3 & NR \\
81 & Howie and Karbhari (1994) & 152 & 38.6 & 0.21 & 0.92 & 54 & 388 & 16.9 & 67.3 & NR \\
82 & Howie and Karbhari (1994) & 152 & 38.6 & 0.21 & 0.92 & 54 & 388 & 16.9 & 64.7 & NR \\
83 & Howie and Karbhari (1994) & 152 & 38.6 & 0.21 & 1.22 & 27.7 & 388 & 11.5 & 52.7 & NR \\
84 & Howie and Karbhari (1994) & 152 & 38.6 & 0.21 & 1.22 & 27.7 & 1,577 & 11.5 & 49.3 & NR \\
85 & Howie and Karbhari (1994) & 152 & 38.6 & 0.21 & 1.22 & 27.7 & 1,577 & 11.5 & 52.6 & NR \\
\hline
\end{tabular}

NR: Not reported by the authors.

${ }^{a}$ Tasdemir et al. (1998) Eq. 14 was used because $\varepsilon_{c o}$ was not reported by the authors.

comparison. Therefore, the model proposed in this study, derived by modifying Richart et al. (1928) model, is only valid for carbon FRP confined concrete cylinders. The strength and strain characteristics of carbon FRP sheets were determined by the researchers themselves. Studies using producer-supplied values for FRP materials were excluded from this research.

In Table 1-using the reported dimensions of concrete cylinders, concrete strengths and FRP characteristics determined by coupon tests $-K_{N}$ values were calculated for each confined concrete cylinder using Eq. 9. When $\varepsilon_{c o}$ was not specified, Eq. 14, which was proposed by Tasdemir et al. (1998), was used:

$$
\varepsilon_{c o}=\left(-0.067 f_{c o}^{\prime 2}+29.9 f_{c o}^{\prime}+1053\right) 10^{-6}
$$

\section{Model Comparison}

This section discusses the accuracy of the predictions made by the proposed model: modified Richart et al. (1928), Mander et al. (1988a) considering premature failure of FRP confinement by using Eq. 10, and the current recommended equations by ACI440.2R (2008).

The confined strength $\left(f_{c c}^{\prime}: f_{c o}^{\prime}\right)$ and corresponding strain $\left(\varepsilon_{c c}: \varepsilon_{c o}\right)$ values were calculated using relevant equations of each model. They were compared with the test results of FRP confined concrete, shown in Table 1, whenever corresponding results are reported by the researchers.

The accuracy of each model was then quantitatively evaluated by computing the average absolute percent error $\left(e r r_{\text {avg }}\right)$ for confined strength $\left(f_{c c}^{\prime}: f_{c o}^{\prime}\right)$ and corresponding strain $\left(\varepsilon_{c c}: \varepsilon_{c o}\right)$ values as follows:

$$
\begin{gathered}
e r r_{a v g}=\frac{\sum_{i=1}^{N}\left|e r r_{i}\right|}{N} \\
e r r_{i}=\frac{f_{c c, P}^{\prime}-f_{c c}^{\prime}}{f_{c c}^{\prime}} \times 100 \quad \text { or } \quad e r r_{i}=\frac{\varepsilon_{c c, P .}-\varepsilon_{c c .}}{\varepsilon_{c c}} \times 100
\end{gathered}
$$

where $e r r_{i}=$ percent error in the predicted values of confined 255 values $\left(\varepsilon_{c c, P}.\right)$ using Eq. 15 , and $N=$ the number of tests reporting $f_{c c}^{\prime}$ or $\varepsilon_{c c}$ values, which are the experimentally-observed values of confined strength and the corresponding axial strain values, respectively. All 85 tests shown in Table 1 reported $f_{c c}^{\prime}$ values; however, only 64 reported corresponding $\varepsilon_{c c}$ values. For $f_{c c}^{\prime}$ or $\varepsilon_{c c}$, the accurate prediction line is achieved by assuming an ideal model, which predicts exactly the same values as experimental results, which in turn can be expressed as a straight line that produces a $45^{\circ}$ angle to the experimental results axis.

The accuracy of the models was also compared by calculating the sum of squared errors over the $f_{c c}^{\prime}$ or $\varepsilon_{c c}$ values reported in Table 1 . The error for each data point was calculated by the difference between the experimental and predicted values. The model providing a smaller sum of squared errors was accepted as a better model than the other two models.

\section{Comparison of $f_{c c}^{\prime} / f_{c o}^{\prime}$ Predictions}

For each test notd in Table $1, f_{c c}^{\prime}: f_{c o}^{\prime}$ values were calculated using Eqs. 3, 4 and 11 for Mander et al. (1988a), ACI 440-2R (2008) and the proposed model, respectively. Observed results and predicted values are plotted in Fig. 4.

To measure and compare the models' accuracy Eqs. 15 and 16 were used. Other than an overall comparison taking all tests into consideration, a separate comparison was made for tests with $K_{N}$ values between 10 and 20 because of ACI 440-2R (2008) recommendations for stress and strain limitations, which were explained previously in this paper.

The proposed model gave better predictions for $f_{c c}^{\prime}: f_{c o}^{\prime}$ values than the other two models for both the overall and $K_{N}$ values between 10 and 20, with average absolute errors of 7.23 and $7.44 \%$, respectively (Fig. 5) Eq. 4, recommended by ACI 440-2R (2008), yielded the second-best predictions, with average absolute errors of 8.79 and $8.26 \%$, respectively. Although the premature failure of FRP confinement was considered, Mander et al. (1988a) Eq. 3 could predict $f_{c c}^{\prime}: f_{c o}^{\prime}$ values with larger average absolute errors (12.21 and $14.15 \%$, respectively).

The accuracy of the three models, concerning the $f_{c c}^{\prime}: f_{c o}^{\prime}$ values over the given database, was also compared by calculating the sum of the squared errors for each model (Fig. 6). A smaller sum of 


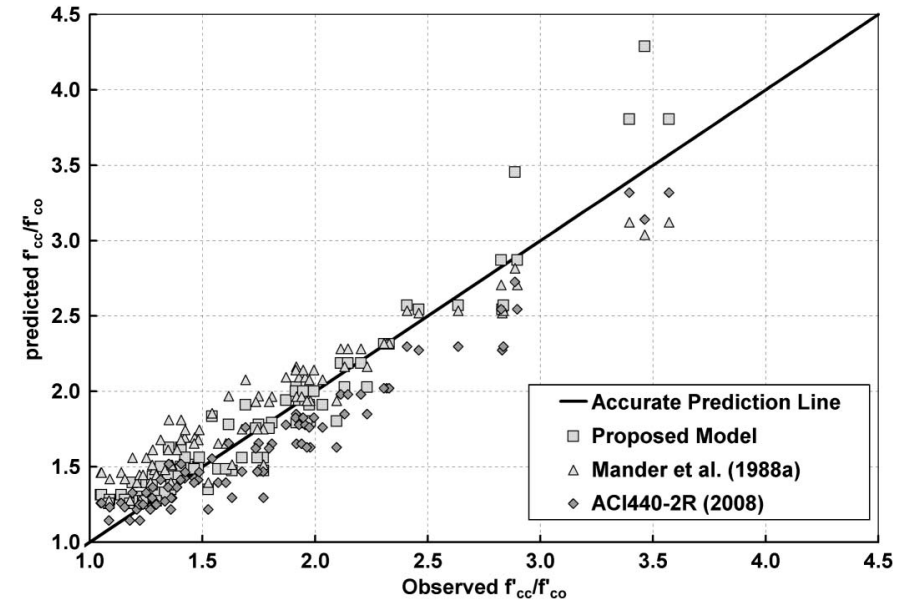

F4:1

Fig. 5. Accuracy comparisons for $f_{c c}^{\prime}: f_{c o}^{\prime}$ amongst the strength models using the average absolute error method

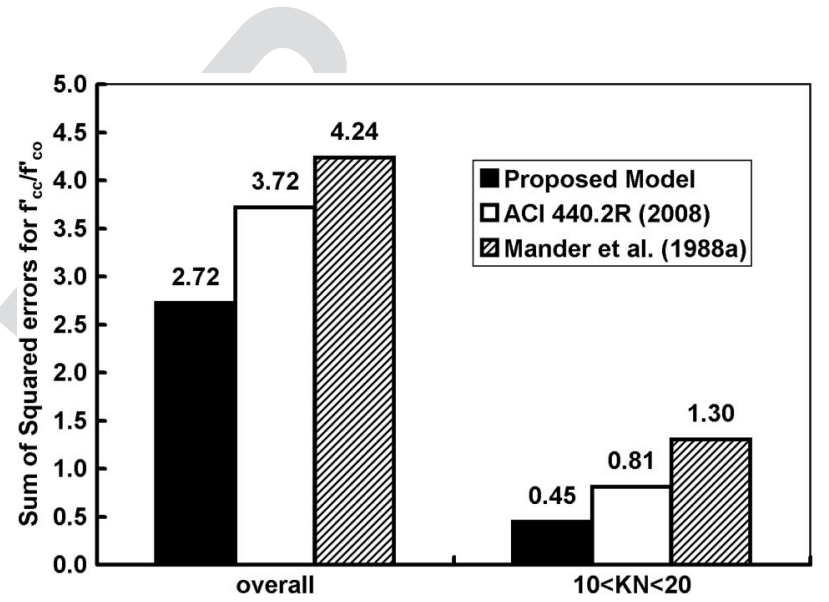

F6:1 Fig. 6. Accuracy comparisons for $f_{c c}^{\prime}: f_{c o}^{\prime}$ amongst the strength models F6:2

Fig. 4. Observed vs predicted values for $f_{c c}^{\prime}: f_{c o}^{\prime}$ using different strength models

squared errors also indicated that the proposed model is more accurate than the other two models in predicting $f_{c c}^{\prime}: f_{c o}^{\prime}$ values over the given database. The order of the accuracy of the models remained the same for the sum of squared errors method.

For experimental $f_{c c}^{\prime}: f_{c o}^{\prime}$ values larger than 3.0, the proposed model yielded unconservative predictions, whereas Mander et al. (1988a) Eq. 3 and ACI 440-2R (2008) recommended Eq. 4 yielded

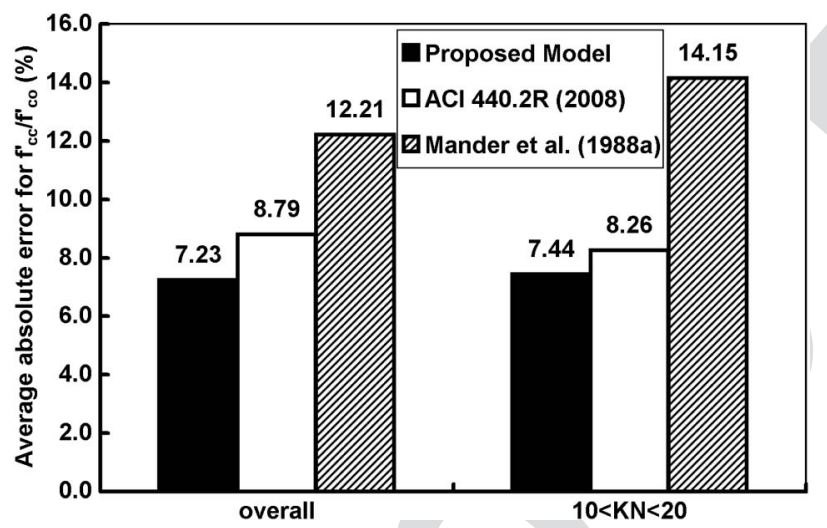

using the sum of squared errors method conservative predictions. The unconservative predictions may be attributed to the linear expression of the original model in terms of the $f_{l}: f_{c o}^{\prime}$ value as given by Eq. 1 , which exhibits a constant slope of 4.1. ACI 440-2R (2008) recommended Eq. 4 is also a linear equation in terms of $f_{l}: f_{c o}^{\prime}$; however, its slope is 3.3 (when $\psi=1.0$ ) and always gives a more conservative prediction than Richart et al. (1928) model. Mander et al. (1988a) Eq. 3 is expressed as a non-linear function of $f_{l}: f_{c o}^{\prime}$ and exhibits a decreasing slope as $f_{l}: f_{c o}^{\prime}$ increases. In practice, achieving confinement ratios so as to obtain $f_{c c}^{\prime}: f_{c o}^{\prime}$ ratios higher than 3.0 is quite difficult and requires a large amount of confinement material. Thus, the proposed model's unconservative predictions for experimental values of $f_{c c}^{\prime}: f_{c o}^{\prime}$ higher than 3.0 can be ignored.

\section{Comparison of $\varepsilon_{c c} / \varepsilon_{c o}$ Predictions}

The calculated average absolute error values for $\varepsilon_{c c}: \varepsilon_{c o}$ were larger than that of $f_{c c}^{\prime}: f_{c o}^{\prime}$ predictions for all three models under discussion. However, the ACI 440-2R (2008) model was slightly better than the other two models on the overall database, with an average absolute error of $29.30 \%$. For $K_{N}$ values between 10 and 20, all three models gave similar results close to $30 \%$ (Figs. 7 and 8).

When the accuracy of the models were compared by the sum of squared errors (Fig. 9), the ACI 440-2R (2008) model was again better than the other two models in predicting the $\varepsilon_{c c}: \varepsilon_{c o}$ values over the given database. Though Mander et al. (1988a) model

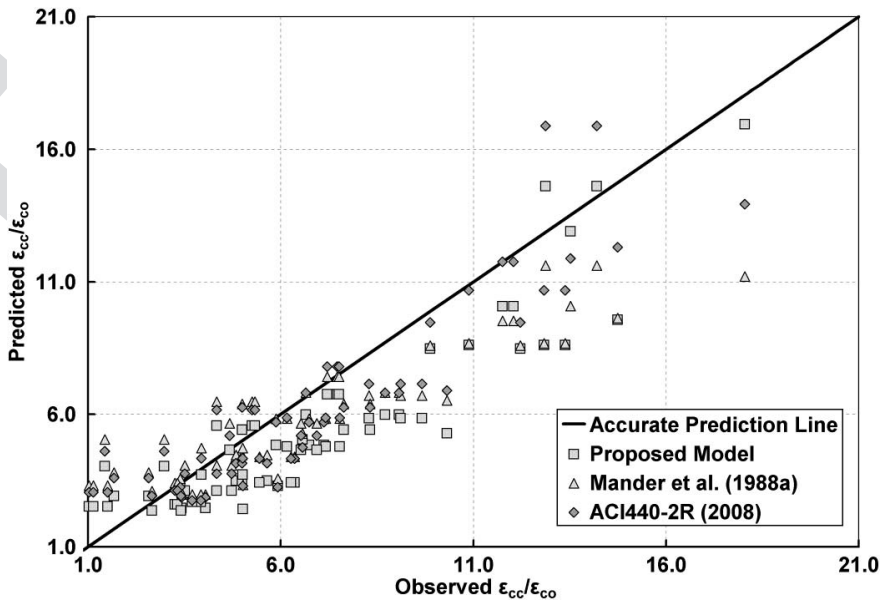

Fig. 7. Observed vs predicted values for $\varepsilon_{c c}: \varepsilon_{c o}$ using different strength models

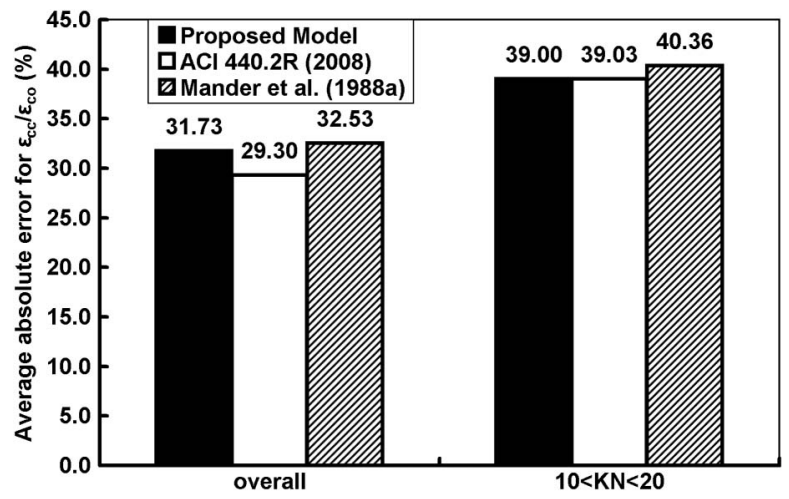

Fig. 8. Accuracy comparisons for $\varepsilon_{c c}: \varepsilon_{c o}$ amongst the models using the average absolute error method 


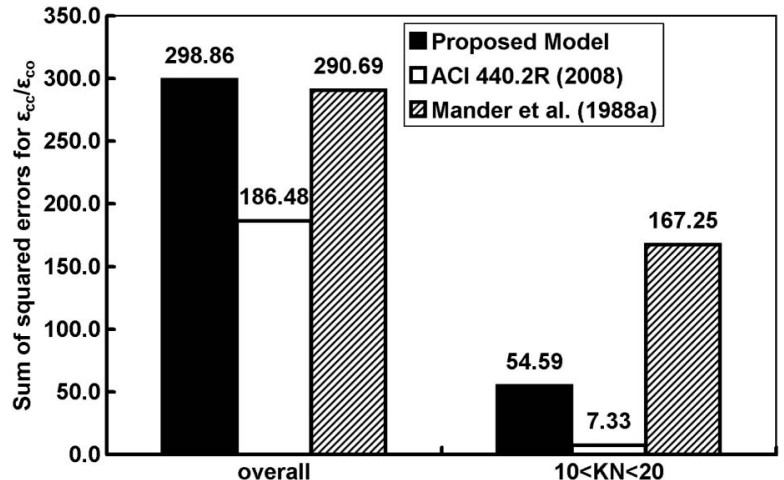

F9:1 Fig. 9. Accuracy comparisons for $\varepsilon_{c c}: \varepsilon_{c o}$ amongst the strength models F9:2 using the sum of squared errors method

yielded the second-best predictions for the overall database of $\varepsilon_{c c}: \varepsilon_{c o}$ values, for $K_{N}$ values between 10 and 20, the proposed model was better than Mander et al. (1988a) and gave second-best predictions, after the ACI 440-2R (2008) model for this range.

\section{Extending the Proposed Model to Hollow Concrete Columns Confined with FRP}

Having shown that the proposed model can predict maximum axial stress and the corresponding axial strain values with no less accuracy than the other two models, this research attempted to extend this model to hollow concrete columns with FRP confinement.

Since the model was proposed for solid specimens with circular cross-sections confined with carbon FRP, Eqs. 11 and 12 were modified by multiplying the right sides of the equations by a coefficient $\beta$ (Eq. 17) to account for the different confinement mechanism in hollow columns, which was explained by Fam and Rizkalla (2001), Lignola et al. (2008) and Yazici and Hadi (2009):

$$
\beta=\left(1-\frac{D_{i}^{2}}{D_{o}^{2}}\right)
$$

where $D_{i}=$ hollow core diameter of the concrete cylinder and $D_{o}=$ outer diameter of the concrete cylinder. Hence, the modified forms of Eqs. 11 and 12 become:

$$
\begin{aligned}
& \frac{f_{c c}^{\prime}}{f_{c o}^{\prime}}=\left(1+0.033 K_{N}\right)\left(1-\frac{D_{i}^{2}}{D_{o}^{2}}\right) \\
& \frac{\varepsilon_{c c}}{\varepsilon_{c o}}=\left(1+0.16 K_{N}\right)\left(1-\frac{D_{i}^{2}}{D_{o}^{2}}\right)
\end{aligned}
$$

The reason for multiplying Eqs. 11 and 12 with $\beta$ is that the tests done by researchers (Fam and Rizkalla 2001; Modarelli et al. 2005; Zahn et al. 1990) on hollow concrete columns have suggested that confinement efficiency decreases as the hollow diameter increases. Thus, the authors of this paper found it appropriate to decrease the expected values of $f_{c c}^{\prime}: f_{c o}^{\prime}$ and $\varepsilon_{c c}: \varepsilon_{c o}$ by multiplying Eqs. 11 and 12 by $\beta$. However, while calculating the value of $K_{N}$ using Eq. 9 , the outer diameter $\left(D_{o}\right)$ was used, and $f_{c o}^{\prime}$ and $\varepsilon_{c o}$ values was taken as the compressive strength and corresponding axial strain of standard solid concrete cylinders $(100 \times 200 \mathrm{~mm}$ or $150 \times 300 \mathrm{~mm})$, respectively.

Since the model was developed using carbon FRP wrapped concrete cylinders, only the tests performed on hollow cylinders confined by carbon FRP could be used for calculation of accuracy. Thus, the test results reported by Modarelli et al. (2005) in Table 2 were used in this section. Two different batches of concrete were used in this study, and they exhibited 28.35 and $38.24 \mathrm{MPa}$ compressive strengths $\left(f_{c o}^{\prime}\right)$, with corresponding axial strains $\left(\varepsilon_{c o}\right)$ of 0.0049 and 0.0063 , respectively.

Experimental results versus the predicted values of $f_{c c}^{\prime}: f_{c o}^{\prime}$ and $\varepsilon_{c c}: \varepsilon_{c o}$, using Eqs. 18 and 19, were plotted in Figs. 10 and 11, respectively. As in solid samples, $f_{c c}^{\prime}: f_{c o}^{\prime}$ calculations yielded a better accuracy than $\varepsilon_{c c}: \varepsilon_{c o}$ calculations. The average absolute error in $f_{c c}^{\prime}: f_{c o}^{\prime}$ predictions concerning the overall database and $K_{N}$ values between 10 and 20 were calculated to be 5.97 and $6.95 \%$, respectively. The average absolute error values in $\varepsilon_{c c}: \varepsilon_{c o}$ predictions were 26.29 and $23.42 \%$, respectively (Fig. 12). However, the number of experiments for carbon FRP confined hollow concrete cylinders reported in the literature may be limited. The proposed model was developed using the solid cylinder test results and still provided good results in hollow cylinders after introducing the coefficient $\beta$ into Eqs. 11 and 12.

\section{Discussion}

Being the most commonly used equations in steel confined concrete strength and corresponding strain calculations, Richart et al. (1928) Eqs. 1 and 2 were used to derive the new model, and it was quite effective for FRP confined concrete after simple modifications such as accounting for premature failure of FRP confinement. The predictions of ultimate strength and the corresponding axial strain of FRP confined concrete cylinders using proposed Eqs. 11 and 12 were at least as effective as Mander et al. (1988a) and the ACI440.2R-08(2008) model.

Having proven the proposed model's effectiveness, with an attempt to extend the model to FRP confined hollow concrete cylinders, a coefficient $\beta$ (Eq. 17) was introduced into Eqs. 11 and 12, which rendered them quite effective in predicting the FRP confined concrete strength and corresponding strain values.

Table 2. Experimental Results for Carbon FRP Confined Hollow Concrete Cylinders: Data from Modarelli et al. (2005)

\begin{tabular}{|c|c|c|c|c|c|c|c|c|}
\hline Label & Dimensions $(\mathrm{mm}) h \times D_{o}$ & $f_{c o}^{\prime}(\mathrm{MPa})$ & Hollow diameter $(\mathrm{mm}) D_{i}$ & $t_{f}(\mathrm{~mm})$ & $E_{f}(\mathrm{GPa})$ & $K_{N}$ & $f_{c c}^{\prime}: f_{c o}^{\prime}$ & $\varepsilon_{c c}: \varepsilon_{c o}$ \\
\hline $\mathrm{CC} 2$ & $300 \times 150$ & 28.35 & 50 & 0.165 & 221 & 17.1 & 1.59 & 4.59 \\
\hline $\mathrm{CC} 3$ & $300 \times 150$ & 28.35 & 50 & 0.330 & 221 & 34.3 & 1.79 & 5.20 \\
\hline $\mathrm{CC} 4$ & $300 \times 150$ & 28.35 & 50 & 0.495 & 221 & 51.4 & 2.52 & 6.30 \\
\hline CC6 & $300 \times 150$ & 38.24 & 50 & 0.165 & 221 & 12.7 & 1.25 & 2.42 \\
\hline CC7 & $300 \times 150$ & 38.24 & 50 & 0.330 & 221 & 25.4 & 1.55 & 2.71 \\
\hline $\mathrm{CC} 8$ & $500 \times 250$ & 28.35 & 150 & 0.165 & 221 & 10.3 & 0.94 & 3.22 \\
\hline $\mathrm{CC} 9$ & $500 \times 250$ & 28.35 & 150 & 0.330 & 221 & 20.6 & 1.20 & 3.37 \\
\hline $\mathrm{CC} 10$ & $500 \times 250$ & 28.35 & 150 & 0.495 & 221 & 30.9 & 1.27 & 4.57 \\
\hline $\mathrm{CC} 11$ & $500 \times 250$ & 38.24 & 150 & 0.165 & 221 & 7.6 & 0.83 & 1.94 \\
\hline $\mathrm{CC} 12$ & $500 \times 250$ & 38.24 & 150 & 0.330 & 221 & 15.3 & 1.02 & 2.38 \\
\hline
\end{tabular}




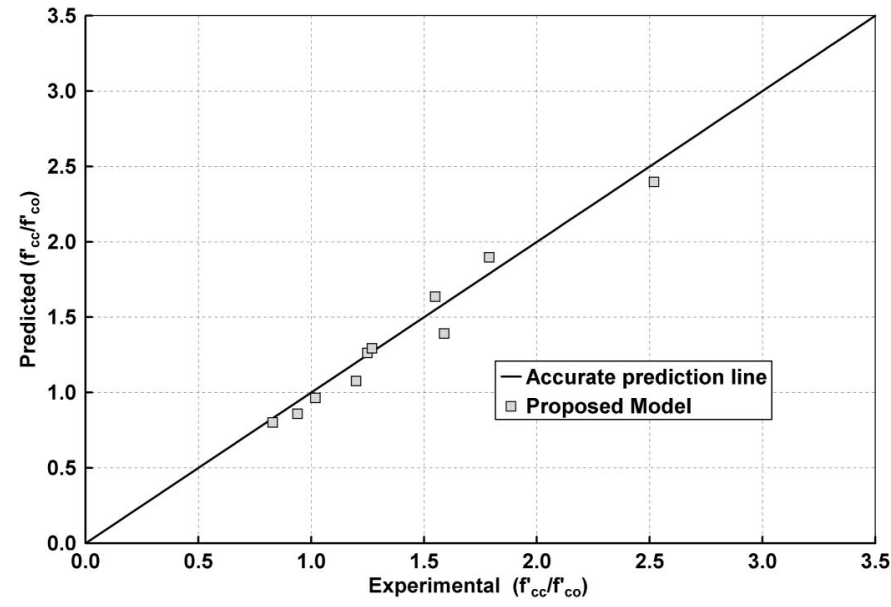

F10:1

F10:2

Fig. 10. Experimental versus predicted values of $f_{c c}^{\prime}: f_{c o}^{\prime}$ for hollow concrete cylinders

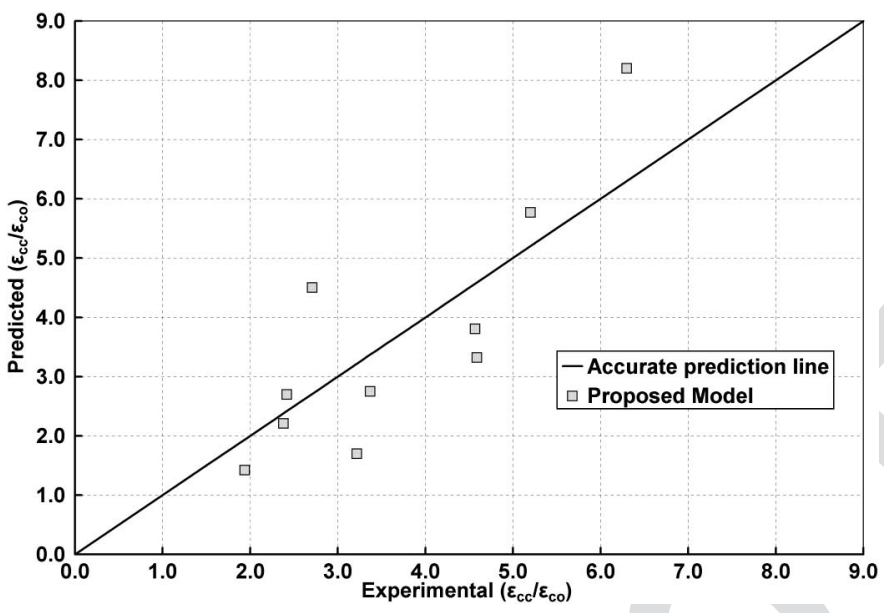

F11:1

Fig. 11. Experimental versus predicted values of $\varepsilon_{c c}: \varepsilon_{c o}$ for hollow concrete cylinders

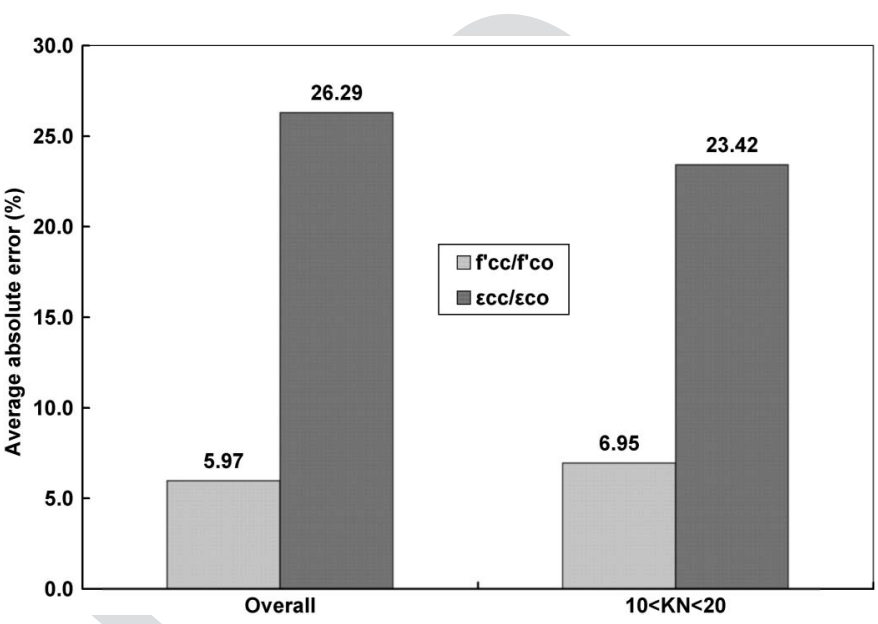

F12:1

F12:2 result was reported by De Lorenzis and Tepfers (2003) for
confinement models which were not discussed in this study.

All of the models under discussion in this study have predicted $f_{c c}^{\prime}: f_{c o}^{\prime}$ values with a higher accuracy than $\varepsilon_{c c}: \varepsilon_{c o}$ values. A similar

\section{Conclusion}

A simple ultimate strength and corresponding axial strain model for FRP confined concrete was developed using Richart et al. (1928) model, which was originally proposed for predicting the behavior of concrete under active and passive confinement. Although the proposed model was originally proposed approximately 83 years ago, after necessary modifications it can still be used for predicting the behavior of FRP confined concrete. This study has demonstrated that existing equations for predicting the strength of steel confined concrete can also be used for FRP confined concrete if premature failure of FRP confinement is considered. However, the error margin for predicting axial strain values of FRP confined concrete was higher than the strength predictions.

The model was extended to hollow core cylinders and was quite effective. The authors believe the model's ability to handle both solid and hollow cylinders is quite effective, and the simplicity of the proposed equations is worthy of attention.

\section{References}

American Concrete Institute (ACI). (2002). "Guide for the design and construction of externally bonded FRP systems for strengthening concrete structures." 440.2R-02, Farmington Hills, MI.

American Concrete Institute (ACI). (2008). "Guide for the design and construction of externally bonded FRP systems for strengthening concrete structures." 440.2R-08, Farmington Hills, MI.

Balmer, G. G. (1949). "Shearing strength of concrete under high triaxial stress-Computation of Mohr's envelope curve." Rep. SP-23, U.S. Bureau of Reclamation Structure Research Lab, Denver.

Candappa, D. P., Setunge, S., and Sanjayan, J. G. (1999). "Stress versus strain relationship of high strength concrete under high lateral confinement." Cem. Concr. Res., 29(12), 1977-1982.

Considère, A. (1906). Experimental researches on reinforced concrete, McGraw, New York, 242.

De Lorenzis, L., Micelli, F., and La Tegola, A. (2002). "Influence of specimen size and resin type on the behavior of FRP-confined concrete cylinders." Advanced polymer composites for structural applications in construction, Thomas Telford, London 231-239.

De Lorenzis, L., and Tepfers, R. (2001). "A comparative study of models on confinement of concrete cylinders with FRP composites." Rep. No 01:04, Dept. of Building Materials, Chalmers Univ. of Technology, Gothenburg, Sweden.

De Lorenzis, L., and Tepfers, R. (2003). "Comparative study of models on confinement of concrete cylinders with fiber-reinforced polymer

Elwi, A. A., and Murray, D. W. (1979). "A 3D hypoelastic concrete constitutive relationship." J. Eng. Mech. Div., 105(4), 623-641.

Fam, A., and Rizkalla, S. H. (2001). "Confinement model for axially loaded concrete confined by circular fiber-reinforced polymer tubes." $A C I$ Struct. J., 98(4), 451-461.

Gardner, N. J. (1969). "Triaxial behavior of concrete." ACI J. Proc., 66(2), 136-158.

Harries, K. A., and Carey, S. A. (2003). "Shape and gap effects on the behaviour of variably confined concrete." Cem. Concr. Res., 33(6), 881-890.

Howie, I., and Karbhari, V. M. (1994). "Effect of materials architecture on strengthening efficiency of composite wraps for deteriorating columns in the North-East." Proc. 3rd Materials Engineering Conf., ASCE, Reston, VA, 199-206.

Imran, I., and Pantazopoulou, S. J. (1996). "Experimental study of plain concrete under triaxial stress." ACI Mater. J., 93(6), 589-601.

Jiang, T., and Teng, J. G. (2007). "Analysis-oriented stress-strain models for FRP-confined concrete.” Eng. Struct., 29(11), 2968-2986.

Lam, L., and Teng, J. G. (2003a). "Design-oriented stress-strain model for FRP-confined concrete." Constr. Build. Mater., 17(6-7), 471-489. composites." J. Compos. Constr., 7(3), 219-237. 
Lam, L., and Teng, J. G. (2003b). "Design oriented stress-strain model for FRP-confined concrete in rectangular columns." J. Reinf. Plast. Compos., 22(13), 1149-1186.

Lam, L., and Teng, J. G. (2004). "Ultimate condition of fiber reinforced polymer-confined concrete." J. Compos. Constr., 8(6), 539-548.

Lam, L., Teng, J. G., Cheung, C. H., and Xiao, Y. (2006). "FRP-confined concrete under axial cyclic compression." Cem. Concr. Compos., 28(10), 949-958

Lan, S., and Guo, Z. (1997). "Experimental investigation of multiaxial compressive strength of concrete under different stress paths." ACI Mater. J., 94(5), 427-434.

Lignola, G. P., Prota, A., Manfredi, G., and Cosenza, E. (2008). "Unified theory for confinement of RC solid and hollow circular columns." Compos. Part B, 39(7-8), 1151-1160.

Mander, J. B., Priestley, M. J. N., and Park, R. (1988a). "Theoretical stressstrain model for confined concrete." J. Struct. Eng., 114(8), 1804-1826.

Mander, J. B., Priestley, M. J. N., and Park, R. (1988b). "Observed stress-strain behavior of confined concrete." J. Struct. Eng., 114(8), $1827-1849$.

Matthys, S. (2001). "Structural behavior and design of concrete members strengthened with externally bonded FRP reinforcement." Ph.D. thesis, Ghent Univ., Ghent, Belgium.

Matthys, S., Taerwe, L., and Audenaert, K. (1999). "Tests on axially loaded concrete columns confined by fiber reinforced polymer sheet wrapping." Proc. 4th. Int. Symp. on Fiber Reinforced Polymer Reinforcement for Reinforced Concrete Structures, American Concrete Institute, Farmington, MI, 217-229.

Modarelli, R., Micelli, F., and Manni, O. (2005). "FRP-confinement of hollow concrete cylinders and prisms." Proc. 7th Int. Symp. on Fiber Reinforced Polymer Reinforcement for Reinforced Concrete Structures, American Concrete Institute, Farmington, MI, 1-18.

Pessiki, S., Harries, K. A., Kestner, J., Sause, R., and Ricles, J. M. (2001). "The axial behavior of concrete confined with fiber reinforced composite jackets." J. Compos. Constr., 5(4), 237-245.

Richart, F. E., Brandtzaeg, A., and Brown, R. L. (1928). "A study of the failure of concrete under combined compressive stresses." Bulletin 185,
Univ. of Illinois Engineering Experimental Station, UrbanaChampaign, IL.

Richart, F. E., Brandtzaeg, A., and Brown, R. L. (1929). "The failure of plain and spirally reinforced concrete in compression." Bulletin 190, Univ. of Illinois Engineering Experimental Station, UrbanaChampaign, IL.

Rochette, P., and Labossiere, P. (2000). "Axial testing of rectangular column models confined with composites." J. Compos. Constr., 4(3), 129-136.

Sfer, D., Carol, I., Gettu, R., and Etse, G. (2002). "Study of the behavior of concrete under triaxial compression." J. Eng. Mech., 128(2), 156-163.

Smith, S. S., Willam, K. J., Gerstle, K. H., and Sture, S. (1989). "Concrete over the top: Is there life after peak?" ACI Mater. J., 86(5), 491-497.

Spoelstra, M. R., and Monti, G. (1999). "FRP-confined concrete model." J. Compos. Constr., 3(3), 143-150.

Tasdemir, M. A., Tasdemir, C., Jefferson, A. D., Lydon, F. D., and Barr, B. I. G. (1998). "Evaluation of strains at peak stresses in concrete: A threephase composite model approach." Cem. Concr. Compos., 20(4), 301-318.

Watanabe, S., Nakamura, H., Honda, T., Toyoshima, M., Iso, M., and Fujimaki, T. et al. (1997). "Confinement effect of FRP sheet on strength and ductility of concrete cylinders under uniaxial compression." $3 r d$ Int. Symp. of the Japan Concrete Institute, Tokyo, Japan, 233-240.

Xiao, Y., and Wu, H. (2000). "Compressive behavior of concrete confined by carbon fiber composite jackets." J. Mater. Civil Eng., 12(2), 139-146.

Xie, J., Elwi, A E, and MacGregor, J. G. (1995). "Mechanical properties of three high strength concretes containing silica fume." ACI Mater. J., 92(2), 135-145.

Yazici, V., and Hadi, M. N. S. (2009). "Axial load-bending moment diagrams of carbon FRP wrapped hollow core reinforced concrete columns." J. Compos. Constr., 13(4), 262-268.

Zahn, F. A., Park, R., and Priestley, M. J. N. (1990). "Flexural strength and ductility of circular hollow reinforced concrete columns without confinement on inside face." ACI Struct. J., 87(2), 156-166.
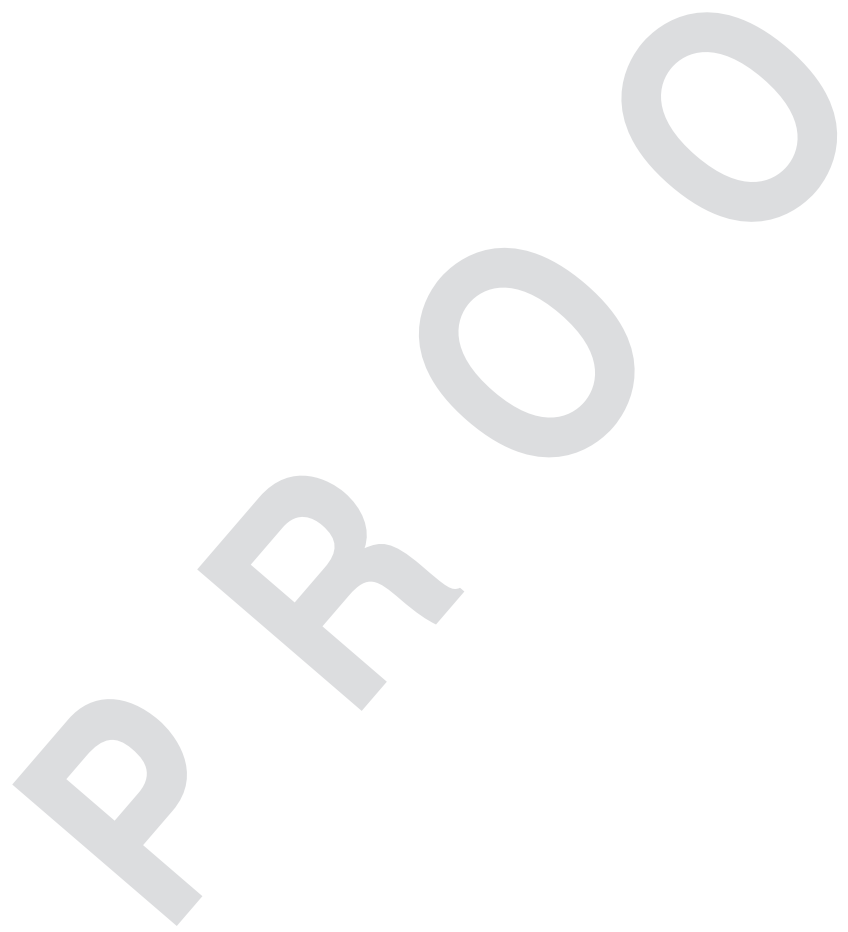